\title{
EVIDENCIAS DE ESTANDARIZACIÓN EN LA MANufactura de CUencos de La Aguada Orilla Norte (Argentina)
}

\author{
Bárbara Balesta, Nora Zagorodny y Celeste Valencia ${ }^{1}$
}

\section{* INTRODUCCIÓN}

Resumen

Se analiza una muestra representativa de cuencos cerámicos de colección asignados a la entidad cultural Aguada del Noroeste

Argentino. Se trata de piezas funerarias provenientes de excavaciones en el cementerio Aguada Orilla Norte del valle de Hualfín, durante la década de 1920 . Nuestro objetivo consistió en la búsqueda de evidencias de estandarización en la manufactura de este tipo de vasijas y en el análisis de su significado en relación a la especialización cerámica en un contexto de desigualdad.

Palabras claves: cerámica funeraria - Aguada - estandarización.

Abstract

In this paper we analyze a representative sample of the funerary vessels belonging to the Aguada culture (Northwest Argentina), recovered in excavations performed in the Aguada Orilla Norte cemetery, in Hualfin Valley, during the 1920 s. It aims to provide evidence on the standardization of this kind of pottery, and its relationship with productive specialization in an unequal society.

Key words: funerary vessels - Aguada - standardization.

Recibido: marzo 2007. Aceptado: mayo 2008.
En el cementerio de La Aguada Orilla Norte, localizado en el valle de Hualfín (Catamarca, Argentina) se excavaron 200 tumbas que contenían un total de 1292 piezas cerámicas. Estas piezas y la documentación que da cuenta de sus contextos de hallazgo pertenecen a la Colección Muñiz Barreto y se hallan en el Museo de La Plata. Los ajuares, recuperados durante la década de 1920, fueron adscritos al período de Integración Regional del Noroeste Argentino (600-1000 DC).

Las vasijas fueron clasificadas tipológicamente (González y Cowgill 1975; González 1977) como Aguada gris grabada, pintada y lisa. Para este estudio se seleccionó la morfología más común a escala cuantitativa, constituida por los cuencos.

Las observaciones preliminares realizadas implican una semejanza aparente entre este tipo de piezas, que ha llevado a suponer que los cuencos de La Aguada Orilla Norte exhiben un rango de variación acotado en cuanto a sus características morfométricas y secuencia de fabricación que se debe a una estandarización en la manufactura. El presente trabajo se centró en la búsqueda de evidencias de estandarización en una muestra representativa de dicho conjunto.

\footnotetext{
${ }^{1}$ Facultad de Ciencias Naturales y Museo, Universidad Nacional de La Plata. Calle 64, nº 3, La Plata, ARGENTINA. Email: bbalesta@ciudad. com.ar; norazago@way.com.ar; celes_valencia@hotmail.com
} 


\section{* Organización de la PROdUCCión cerámica}

La estandarización es una evidencia indirecta de la organización de la producción cerámica, proporcionada por los objetos mismos (Costin 1991). Se caracteriza por una reducción de variedad en la conducta y en el producto; dentro de esto se puede hablar de estandarización en la utilización de materias primas, en los métodos de manufactura (producción masiva, rutinización), en formas, tamaños y colores, entre otros (Rice 1981). Por lo tanto, las evidencias de estandarización se pueden buscar en una serie de atributos tecnológicos que se verán reflejados en la homogeneidad de los materiales, la forma y/o la decoración de las vasijas (Costin y Hagstrum 1995).

En el estudio de la estandarización Costin y Hagstrum (1995) distinguen dos tipos de atributos: intencionales y mecánicos. Los intencionales incluyen propiedades tecnológicas, morfológicas y estilísticas que tienden fundamentalmente a llenar necesidades funcionales y/o sociales. En cambio, los atributos mecánicos son aquellos que introduce el ceramista en forma no intencional. La variabilidad asociada con este tipo de atributos habitualmente se relaciona con el nivel y tipo de tecnología de producción empleada, el entrenamiento, la destreza, la experiencia, la supervisión o calidad del control, los hábitos motores y la conducta idiosincrática. Estas variables incluyen la selección y preparación de recursos; las variaciones en textura y color causadas por diferencias en la preparación de arcillas y pigmentos y fluctuaciones en el horneado; variabilidad en aspectos métricos de los diseños, tales como grosor de las líneas; variaciones menores de tamaño dentro de las clases, y variaciones morfológicas y proporcionales dentro de clases y formas específicas.

Habitualmente la identificación de producción estandarizada se usa para establecer la presencia de especialización, ya que grandes cantidades de productos altamente estandarizados se interpretan como los productos de una o de un número limitado de unidades de producción. Se asume que los sistemas especializados, al tener menos cantidad de productores, exhibirán menor variabilidad (Rice 1981, 1987; Benco
1988; Longacre et al. 1988; Costin y Hagstrum 1995; Sinopoli 1999).

Se suele considerar que los especialistas producen acabados estandarizados a causa de que rutinizan sus tareas $y$, por otra parte, una menor cantidad de ceramistas introducen menos conductas idiosincráticas dentro de un conjunto cerámico (Costin y Hagstrum 1995). Es por ello que algunos autores (Costin 1991; Longacre 1999) plantean que la repetición y la experiencia de un artesano especializado deberían conducir a una regularidad y consistencia en la técnica de manufactura que se reflejará en una mayor homogeneidad en el producto final. Por otra parte, se espera que la destreza se correlacione positivamente con la intensidad de producción, ya que los artesanos que pasan más tiempo en su taller cumplen sus tareas con mayor eficiencia.

Desde estos puntos de vista y enfatizando la estrecha relación entre especialización y estandarización en la producción cerámica, sería posible inferir aspectos del contexto de organización de la producción en forma directa a partir del examen de colecciones arqueológicas y sin necesidad de recurrir al estudio de los sitios específicos de producción. Sin embargo, ha habido discusiones al respecto y se ha argumentado que la estandarización en una producción especializada se debe más a la tasa entre productores y productos que a la destreza y práctica de los especialistas (Stark 1995). Por otra parte, si bien se ha establecido la importancia de la demanda como un factor que afecta la producción estandarizada, sus efectos son altamente variables (Arnold y Nieves 1992). Por ello se sugiere que para el estudio de la estandarización se deben considerar varios aspectos, como la elección de las variables a seleccionar, las características de los conjuntos a comparar, la tecnología y los métodos de análisis (Stark 1995).

Varios trabajos han enfatizado la importancia de la terminología en la definición de la producción estandarizada (Rice 1991; Arnold y Nieves 1992). Rice sugiere tomar a la estandarización como una medida relativa; no pareciéndole adecuado caracterizar a un conjunto específico como "estandarizado" y recomienda que dicho 
término se reserve para un uso de alcance procesual o diacrónico, mientras que para un conjunto cerámico atribuido a un momento particular debería hablarse de "uniformidad". Dicha autora se refiere a la estandarización como una reducción de variedad en la conducta y en el producto, distinguiendo estandarización en la utilización de materias primas, en los métodos de manufactura, en las formas, tamaños y colores, entre otros. Sostiene que las evidencias de estandarización se pueden buscar en el tamaño, la apariencia, la decoración y la manufactura de las piezas.

Ante la ausencia de evidencia directa de producción, como hornos, desechos, herramientas y materias primas, la detección de estandarización y destreza en la producción cerámica resultan de gran utilidad para identificar características específicas de modos de organización en la manufactura cerámica.

En vista de que se pueden esperar diferentes rangos de diversidad en distintos contextos (élite-comunes; doméstico-público; centro-periferia; utilitario-ritual) y en distintos períodos, para los estudios de estandarización es necesario tomar en cuenta niveles de análisis que consideren los rangos de diversidad atribuibles a esos diferentes contextos y en distintos períodos (Rice 1981; Costin 1991).

Por otra parte, la elección lógica consiste en enfocar estos estudios en los aspectos de la variabilidad que reflejen patrones inconscientes, destrezas motoras, sutiles diferencias en tecnología y leves diferencias en materias primas. Es por este motivo que a menudo se seleccionan variables métricas. Luego se pueden contrastar con las variaciones en composición, tecnología y estilo. Las conclusiones se ven reforzadas si en el análisis de dos o más conjuntos de variables se alcanzan resultados complementarios.

\section{Estudios MÉTRICOS}

El estudio de la variación permite comprender el grado de tolerancia para la desviación de tamaños, formas y modos de manufactura, entre otros, establecidos dentro de un grupo. La existencia de una mayor tolerancia implicará mayor variabilidad, mientras que a menor tolerancia disminuirá la variación y se tenderá a la estandarización. Algunos autores han considerado la posibilidad de medir la estandarización y establecer grados de la misma dentro de una producción específica, identificando distintos aspectos sociales a través de la producción homogeneizada de cierto tipo de objetos:

"Standardization, then, is a relative measure of the degree to which artifacts are made to be the same. Standardization is in turn related to the life cycle of the artefact type or class in question, reflecting such things as production costs, consumer preferences, replication and learning behaviours, number of producers, concern with quality, producer skill, and access to resources" (Eerkens y Bettinger 2001: 493-494).

Las variaciones en los atributos métricos son de suma utilidad, ya que nos permiten observar la organización de la producción por constituirse en marcadores de diferentes estrategias de ésta. Uno de los índices más utilizados para establecer la estandarización consiste en la búsqueda de homogeneidad en las medidas de un conjunto de piezas (Blackman et al. 1993; Eerkens y Bettinger 2001; Roux 2003).

Diversos estudios etnográficos y etnoarqueológicos se han concentrado en este tipo de indagación. Longacre (1999), en una investigación llevada a cabo en Filipinas, tomó la variación métrica de un grupo de vasijas para averiguar si la estandarización es el resultado de la rutinización o de conductas repetidas, o si por el contrario depende de la habilidad del ceramista. Para ello eligió sólo una morfología, la jarra de agua y cuatro ceramistas de distintas edades y con distintas categorías en cuanto a su destreza. El análisis estadístico de los datos métricos reveló que el grado de estandarización de las jarras fue la resultante de los esfuerzos deliberados de los ceramistas para fabricar las vasijas que los consumidores esperan en términos de tamaño y forma.

Por otra parte, Roux (2003) comparó estudios etnoarqueológicos en India y en España para aislar parámetros 
involucrados en la estandarización y para cuantificar las relaciones entre intensidad de producción y grado de estandarización. Los resultados sugieren que los distintos grados de estandarización son la resultante de diferentes tasas de producción. Con altas tasas se observa menor variabilidad. Sin embargo, dichos resultados también indicaron que la producción en pequeña escala desarrolla hábitos motores que permiten a los ceramistas producir series estandarizadas de vasijas comparables a las de alta producción.

En el tratamiento de los aspectos morfométricos se han usado procedimientos alternativos que consideran distintas medidas, técnicas y distribuciones poblacionales (Allen 1992; Arnold y Nieves 1992; Kvamme et al.1996). No obstante, las medidas más utilizadas son: altura, diámetro máximo y grosor de las paredes (Longacre 1999; Roux 2003). Esto se relaciona con el hecho de que si se tiene en cuenta que la tasa de producción afecta los hábitos motores, estas medidas son las que más varían de acuerdo a éstos, mientras que los labios y las características estilísticas son los que permiten a los ceramistas expresarse a gusto.

Para establecer comparaciones se considera que el coeficiente de variación (CV) es estable y se puede medir en forma confiable y por lo tanto se utiliza como la medida más adecuada para estudios estadísticos sobre colecciones (Eerkens y Bettinger 2001; Roux 2003).

Con relación al estudio que aquí se propone existe el antecedente de un análisis realizado por Laguens y Juez (2001) sobre 21 cuencos de la Colección Rosso (Museo Ambato de La Falda, Córdoba) procedentes de excavaciones, adscritos a la entidad cultural Aguada. Las variables involucradas fueron: altura total de la pieza, altura del punto angular a la base, altura del punto angular al labio, diámetro máximo, diámetro de la boca, diámetro de la base y espesor de las paredes en el borde. Posteriormente, combinaron las medidas obtenidas de a pares y entre todas. Los resultados obtenidos indicaron muy baja variabilidad con respecto a dichas medidas y una estrecha relación entre ciertas partes del cuerpo. A partir de ello dedujeron una serie de regularidades que fueron adjudicadas a prácticas estandarizadas.

\section{* Breve caracterización de la cultura de La Aguada}

La cultura de La Aguada fue reconocida a fines del siglo XIX a partir de objetos cerámicos en los que se destacaba la imagen del felino. Estos objetos fueron por primera vez publicados por Samuel Lafone Quevedo, a quien se debe la denominación de cerámica draconiana (1892, 1908).

Posteriormente, durante la década de 1920 las expediciones financiadas por Benjamín Muñiz Barreto exhumaron los materiales de contextos funerarios adscritos a dicha entidad cultural que constituyen el objeto de este artículo.

A. R. González ubicó la cultura de La Aguada en el período Medio entre 500 a 900 DC (González 196164, 1998; González y Cowgill 1975), destacando a la cerámica por su excelente manufactura y el complejo simbolismo de sus representaciones, así como la metalurgia del bronce a través de la elaboración de objetos fabricados con la técnica de la cera perdida.

La base económica de la sociedad Aguada fue de tipo agrícola-pastoril, con elaborados sistemas de irrigación complementada con prácticas de caza y recolección. Su integración a una compleja trama de interrelaciones entre diferentes sociedades de los Andes Meridionales establecidas a partir del tráfico caravanero ha sido comentada en diversos trabajos (Núñez y Dillehay 1995 [1979])

Laguens (2007) excavó sitios de habitación correspondientes a esta entidad en el valle de Ambato y planteó que para el siglo V DC se diversifican los roles sociales, se incrementa la cantidad de habitantes, a la vez que se intensifica el uso y explotación del ambiente con la creación y mantenimiento de desigualdades económicas y políticas. Los contextos materiales de la desigualdad social corresponden, en términos de espacio físico a: 
"[...] las diferencias absolutas observadas entre las distintas clases de sitios en cuanto a su tamaño y la relación inversa con respecto a su cantidad dentro de cada clase, donde el acceso diferencial a la tierra para hábitat surge como un contundente diferenciador entre las personas" (2007:44).

Los aspectos ideológico-religiosos se plasmaron en la arquitectura, con la construcción de centros ceremoniales donde se han identificado plataformas, espacios públicos y estructuras monticulares (Gordillo 1994, 2006; González 1998; Callegari 2006; Caro 2006) y en su compleja iconografía que hunde sus raíces en antiguas tradiciones andinas. El llamado "complejo felínico", el culto a los antepasados y el uso de alucinógenos vinculan a Aguada con otras sociedades tanto formativas como del Horizonte Medio de los Andes Centrales (González 1972, 1998; Pérez Gollán 2000).

Respecto de la cerámica, Laguens y Bonnin registran, en referencia a períodos anteriores, una reducción en la variabilidad alfarera, la cual, dentro de un contexto social no igualitario, asocian a "sistemas de producción acotados, posiblemente controlados, usualmente insertos en una organización de la producción en torno a la especialización artesanal" (2005:27).

\section{* Universo de estudio}

El valle de La Aguada se encuentra en el extremo suroeste del valle de Hualfín, a una altura de 1650 m. Fue descrito por Wolters como "[...] un vallecito de más o menos $1 \mathrm{~km}$ de largo y la misma distancia de ancho [...]". (1928-29 Ms:36). Esta localidad fue utilizada como sitio tipo para caracterizar a la cultura homónima (Figura 1).

Los cementerios de esta localidad fueron excavados durante la $10^{\mathrm{a}}$ y $11^{\mathrm{a}}$ expediciones conducidas por Federico Wolters, que abarcaron desde principios de 1928 hasta junio de 1929. Además de los materiales recuperados durante las excavaciones se cuenta con valiosa información obtenida de las libretas de campo que reflejan un registro minucioso, ya que incluyen planos y dibujos de corte y planta de cada una de las tumbas y descripciones del contexto de hallazgo (Figura 2).

El cementerio de La Aguada Orilla Norte está constituido por 200 tumbas, de las cuales 126 corresponden a adultos, 65 a subadultos y nueve son mixtas. La mayoría de los individuos se encuentran inhumados en forma directa, a excepción de 14 entierros en los cuales los cuerpos se hallan depositados en urnas. Hay entierros individuales, que constituyen la modalidad más común, y otros múltiples, que incluyen un máximo de seis individuos por unidad de entierro. En su mayoría, las tumbas presentan estructuras de piedra que delimitan al enterratorio, presentándose como pequeñas paredes que pueden limitar total o parcialmente a los cuerpos enterrados. Por lo general, los individuos están acompañados de cerámica, con un mínimo de una pieza y un máximo de 28 . Sólo siete tumbas no presentan cerámica.

Los ajuares comprenden 1479 objetos de diferentes materias primas: cerámica, piedra, hueso, metal, malaquita y pigmentos. La cerámica es el ítem más numeroso (1292 piezas).

La cerámica que aquí se analiza ha sido clasificada desde el punto de vista tipológico (González y Cowgill 1975; González 1977) como Aguada gris grabada (Figuras 3, 4 y 5), Aguada pintada (Figura 6) y Aguada gris lisa. Posteriormente, González (1998: 77) unificó “una treintena de tipos" en lo que definió como cerámica Hualfín caracterizada por piezas de "color plomizo o gris cocidos en atmósfera reductora, lisos o decorados con líneas finas grabadas". Las variedades de esta cerámica fueron establecidas tomando en cuenta los motivos de la iconografía y algunas de sus características técnicas, consignando que se encuentran vasijas lisas, con motivos geométricos o figurativos. También: "A veces la decoración se hizo con una especie de peine 'arrastrado' de cuatro o cinco puntas. El interior de los diseños grabados se rellena predominantemente con líneas finas transversales" (González 1998: 77). El autor además describe los tipos pintados tanto el bicolor, negro sobre amarillento o amarillo, como 


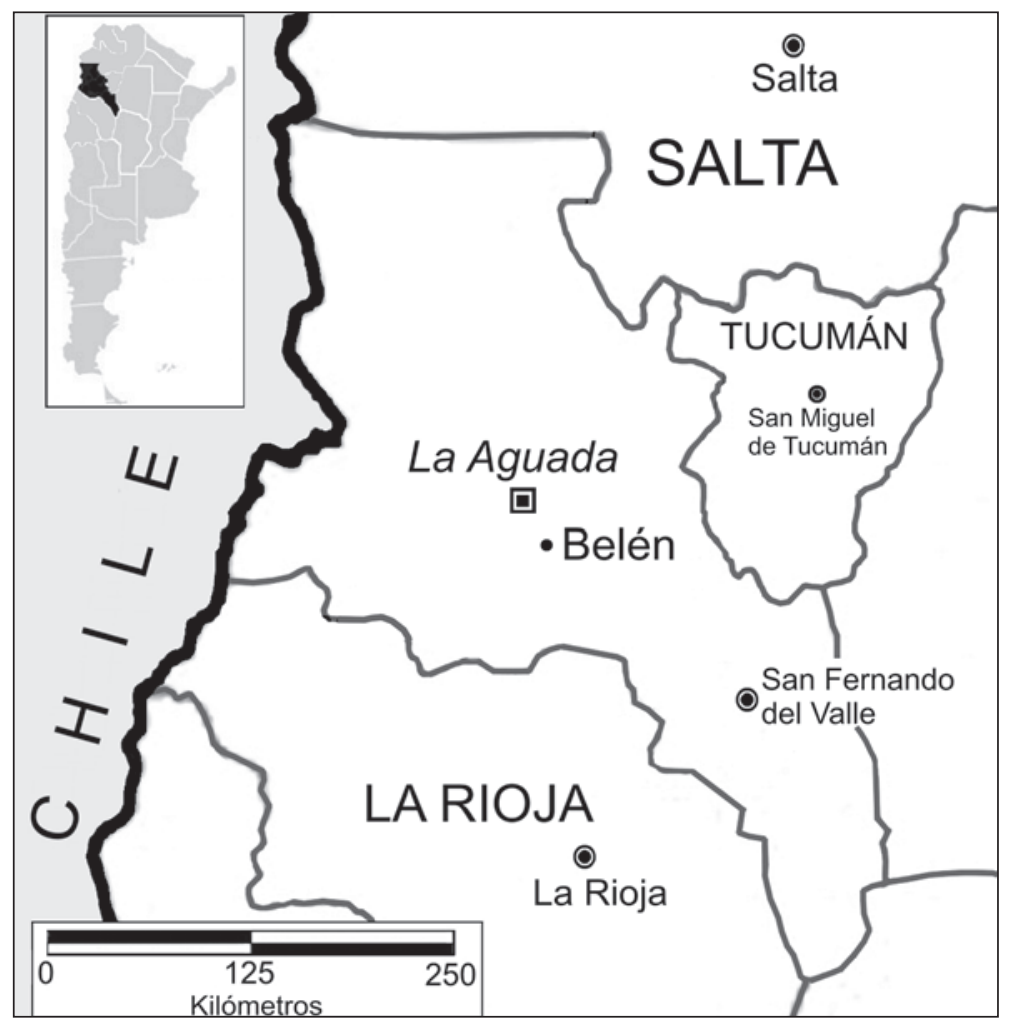

Figura 1. Ubicación de la localidad de La Aguada.

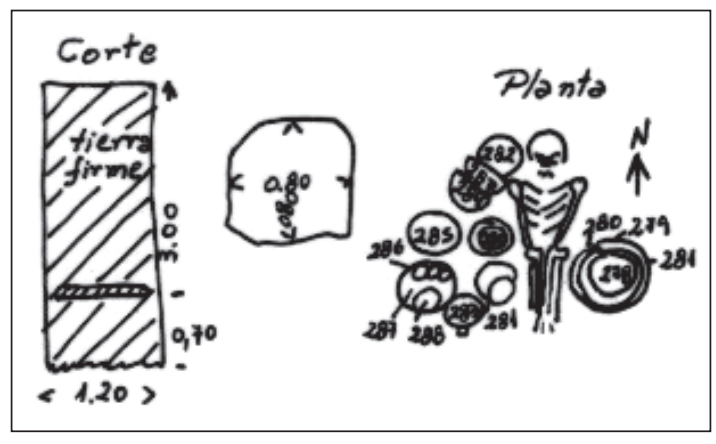

Figura 2. Ejemplo de corte y planta de una tumba del cementerio La Aguada Orilla Norte.

el tipo tricolor, negro y rojo sobre ante amarillento, especificando que a menudo el rojo adquiere tonos púrpura o borravino.

Para González (1998:218) el estilo Hualfín se originó sobre bases de la alfarería Ciénaga, verificándose un cambio en el estilo que indicaría la "progresión de un arte profano a otro de carácter sacro”.

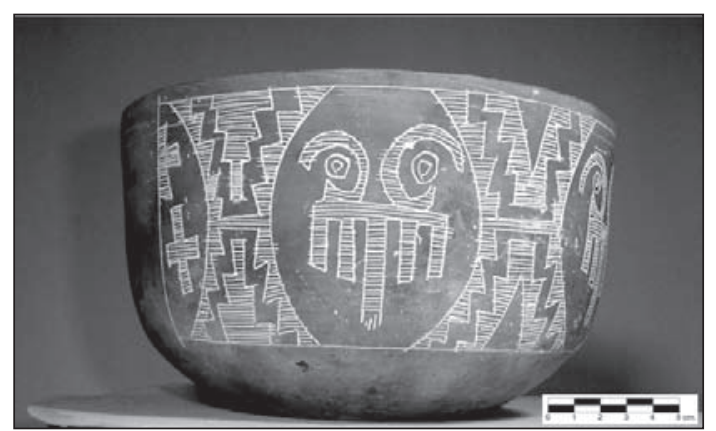

Figura 3. Puco Aguada gris grabado.

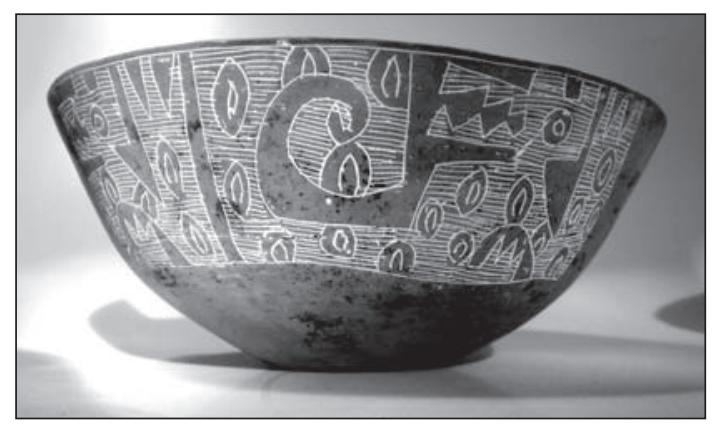

Figura 4. Puco Aguada gris grabado con figura felínica. 


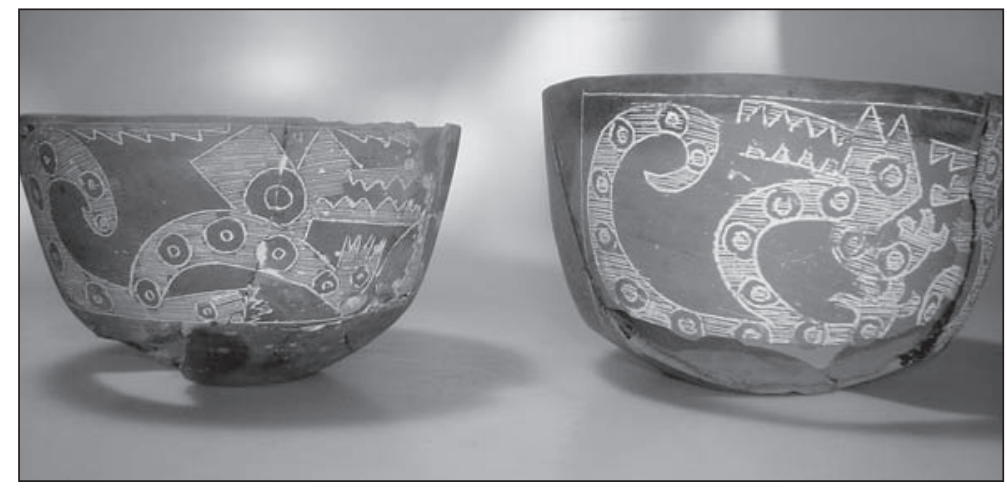

Figura 5. Pucos Aguada gris grabado con figura felínica.

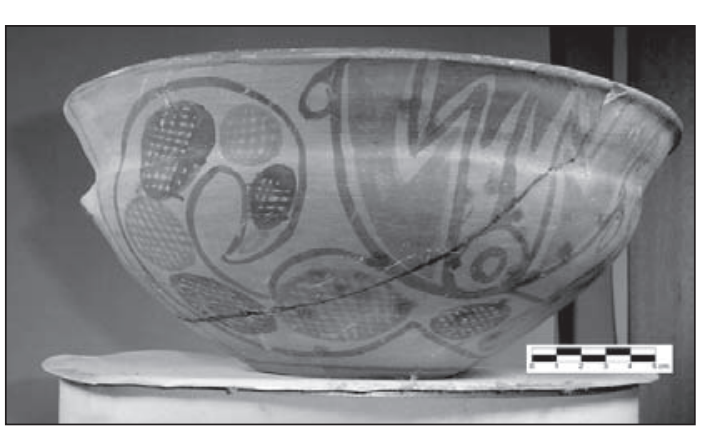

Figura 6. Puco Aguada pintado.

Dentro de las piezas cerámicas de la Colección Muñiz Barreto que corresponden a Aguada, se seleccionó para el estudio la forma más representada, constituida por los cuencos, también denominados "pucos". El término puco es un regionalismo que designa a lo que Balfet y colaboradoras (1992:25) denominan "cuenco". De acuerdo a estas autoras el cuenco corresponde a "una vasija abierta con paredes levemente divergentes y cuyo diámetro de boca (inferior o igual a $18 \mathrm{~cm}$ ) tiene entre una vez y media y dos veces y media la dimensión de la altura." A posteriori extienden y ajustan esta categoría a diámetros mayores de $18 \mathrm{~cm}$. Además, definen dos categorías de acuerdo al diámetro de la boca, manteniendo las relaciones establecidas. Las mismas quedan determinadas como cuenco pequeño con una boca de un diámetro igual o inferior a $11 \mathrm{~cm}$ y cuenco grande cuya boca varía entre 19 y $40 \mathrm{~cm}$. Nosotras hemos establecido una categoría intermedia a la que se ha denominado "cuenco mediano" con una boca comprendida entre 11.1 y $18.9 \mathrm{~cm}$.

\section{Aspectos metodológicos}

El número total de cuencos en La Aguada Orilla Norte asciende a 813 y constituye el $63 \%$ del total de piezas cerámicas de esta porción de la colección. Sobre la base de estas 813 vasijas se tomó una muestra representativa con un nivel de error máximo aceptado de $5 \%$ y un nivel de confianza de $99 \%$. La muestra asciende a 366 vasijas, y se conformó tomando los números de inventario con los que se catalogó cada pieza y que fueron asignados a su ingreso al Museo de La Plata a fin de utilizarlos para fijar un intervalo que garantizara una selección aleatoria.

Se seleccionaron las variables: modelado de la pieza, morfometría, tipo de cocción y técnica decorativa. Dichas variables se corresponden con los atributos mecánicos definidos por Costin y Hagstrum (1995) y por la estandarización definida por Rice (1981) cuyas evidencias se pueden buscar en el tamaño, la apariencia, la decoración y la manufactura de las piezas. Cabe señalar que sobre el universo seleccionado no se pueden realizar estudios de composición de las pastas, ya que se trata de materiales de colección, que no pueden ser sometidos a técnicas destructivas.

Respecto a la morfometría se decidió tener en cuenta: altura total de la pieza, diámetro de la boca y diámetro de la base. Dichas medidas son las más sugeridas para este tipo de estudios y se considera que altura, diámetro máximo y abertura son buenos indicadores para la búsqueda de homogeneidades, ya que son las 
variables que más se modifican de acuerdo con los hábitos motores (Longacre 1999; Roux 2003).

El estudio del modelado incluyó la identificación y caracterización de la secuencia de levantado de los pucos, para lo cual se realizaron estudios experimentales que incluyeron la replicación de piezas.

El tipo de cocción se infirió a partir del color de las superficies interna y externa y a través de la búsqueda de la presencia de núcleos de cocción en piezas incompletas.

Para el análisis de las técnicas decorativas se buscó identificar las herramientas utilizadas y su modo de manipulación, a través de los resultados que incluyeron el tipo y grosor de las incisiones en las piezas con decoración grabada; color, nitidez, grosor, ancho de las pinceladas y conservación de la pintura en las vasijas con decoración pintada. Para las piezas grabadas se utilizó la contrastación con estudios experimentales y para las pintadas se usaron los criterios de Stewart y Adams (1999).

\section{* Variables seleccionadas}

\section{Modelado de las piezas}

A fin de determinar las técnicas puestas en marcha para la manufactura de los pucos se realizó un relevamiento dirigido a identificar las distintas etapas de este proceso, el cual fue contrastado en forma experimental.

La observación se dirigió a la identificación de "huellas" que no han podido ser ocultadas por el alfarero en los momentos finales de la fabricación. Los defectos en la manufactura son una importante herramienta para el arqueólogo en el proceso de reconstrucción de la cadena operativa. Dichos defectos se evidencian a partir del reconocimiento de alteraciones en distintos sectores de las superficies tanto interna como externa de las piezas. ${ }^{2}$ La cadena operativa detectada en la

\footnotetext{
2 Las vasijas que componen la porción Aguada de la colección y, especialmente los pucos, constituyen una prueba del nivel de
}

producción de los cuencos estudiados involucra las siguientes etapas:

1) Confección de la base. La base fue construida a partir de una plancha cortada en círculo o de una bola aplastada. Esto se infiere a partir del registro de diferencias de espesor en forma horizontal y de la presencia de rajaduras horizontales en el límite entre la base y el comienzo de la pared de la pieza (Figura 7). La construcción deficiente de la base por unión de rollos concéntricos genera rajaduras con diseño espiralado. La ausencia en el registro de este tipo de defecto, sumada a la presencia de los otros tipos de rajaduras avala la interpretación acerca de que la construcción se realizó a partir de un solo trozo de material.

2) Confección del cuerpo. Se identificaron huellas que revelan la confección de las paredes del cuerpo a partir de rollos superpuestos. Las huellas consisten en irregularidades en el espesor de la pared a modo de surcos horizontales que diferencian bandas de aproximadamente $2 \mathrm{~cm}$ de ancho y/o rajaduras en las zonas de unión de los rollos siguiendo su dirección horizontal. En la Figura 8 se puede notar el aplanamiento y la costura de dos rollos de arcilla realizada con herramienta. En los cuencos que presentan punto de inflexión en su perfil se observa, en ciertos casos, una diferencia de espesor entre el sector inferior y el sector superior de la pared. En este punto, ocasionalmente, pueden exhibir rajaduras horizontales. En la cara interna de los cuencos se registraron ondulaciones de trayectoria vertical. A nivel experimental esta situación se reprodujo presionando el rollo en sentido vertical a medida que se iba colocando. Esta acción mejora la adherencia entre los rollos y permite adelgazar y controlar el espesor de las paredes.

excelencia que alcanzó su producción alfarera. Es por ello que sólo en 23 piezas analizadas se detectaron alternativamente algunas deficiencias que permitieron reconstruir la secuencia de manufactura. Se ha considerado que dicho número, si bien es relevante para el registro de la secuencia, no es significativo para la aplicación de técnicas estadísticas, por lo cual no se presentan cuadros para la variable "modelado". 


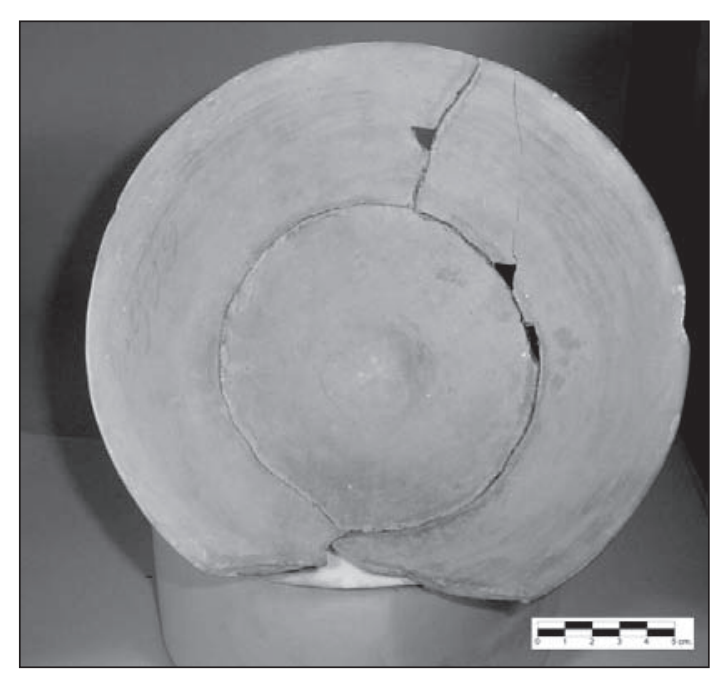

Figura 7. Registro de rajadura total entre pared y base y evidencia de pulido en líneas

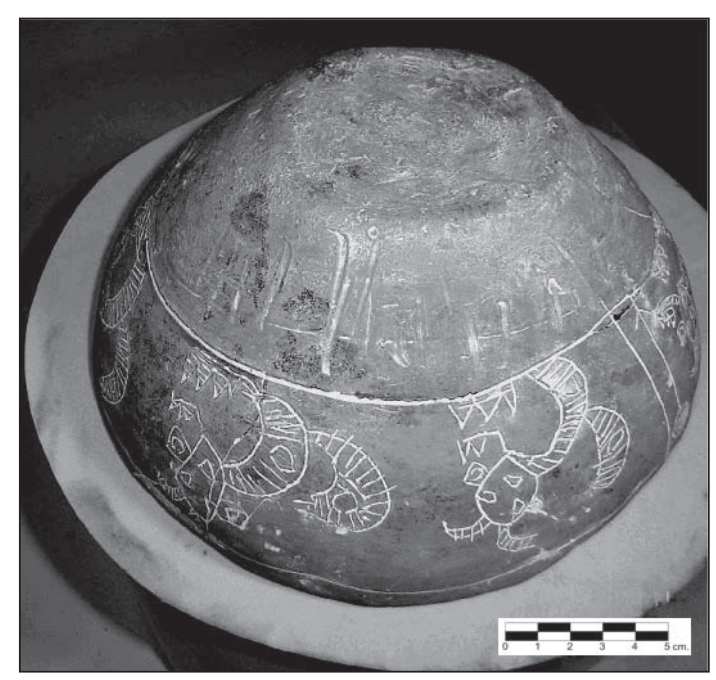

Figura 8. Evidencia de costura de rollos con herramienta.

3) Confección del borde. A nivel morfológico la muestra presenta bordes de tipo directo con distintos tipos de secciones: redondeadas 61\%; cuadradas 34\% yen bisel $5 \%$. El borde exhibe un recorrido regular y la pieza presenta la misma altura (base-borde) en toda su extensión, de lo que se infiere que el alfarero tuvo especial cuidado en el levantado del cuerpo u optó por recortarlo. En algunos casos se observó la existencia de rebarba. Las tareas de experimentación indicaron que la rebarba se puede producir durante el proceso de adelgazamiento de las paredes, por eliminación de material y/o durante el pulido, cuando el material se acomoda hacia el borde.

4) Alisado de superficie y adelgazamiento de las paredes. En los pucos relevados este procedimiento implicó una acción fundamental a los fines de obtener paredes delgadas y de grosor uniforme. El adelgazamiento se realizó eliminando material en toda la extensión de las paredes con una herramienta plana hasta lograr el espesor deseado. Esta acción fue reconocida a partir de dos evidencias: a) presencia de líneas como consecuencia del arrastre del material en ambas superficies o sólo en alguna de ellas, y b) existencia de una rebarba mayoritariamente en el sector externo del borde y en menor proporción en el sector interno. En algunos casos, esta práctica se pudo observar por debajo del pulido a través de una diferencia en la coloración.

En general, el grosor de las paredes se redujo desde la cara externa del puco. Esta acción quedó registrada en las diferencias de acabado de ambas superficies. Mientras que la superficie externa es lisa y uniforme, la interna conserva ciertas irregularidades producto de su confección como, por ejemplo, irregularidades horizontales en la zona de unión de los rollos y verticales como resultado de la presión sobre éstos. Otra clase de evidencia corresponde a lo que denominamos estrías. Las estrías son finas líneas paralelas principalmente de disposición horizontal que quedan como impronta en el proceso de alisado. Experimentalmente, esta huella puede ser reproducida humedeciendo la superficie con un trapo o con un marlo de maíz. Las estrías son de aparición ocasional, ya que generalmente quedan ocultas por las maniobras de pulido.

Otro tipo de huella es la producida por el arrastre de partículas; estas trazas también son de morfología lineal y con sentido horizontal. Las impurezas de la pasta al ser arrastradas con una herramienta dejan una marca que señala la trayectoria del movimiento sobre la arcilla húmeda.

5) Acabado de superficie final. Los cuencos Aguada presentan como acabado de superficie final la técnica de pulido en líneas (ver Figura 7), en el sector interno 
de la pieza. El pulido puede variar en su dirección. Los cuencos de perfil compuesto presentan en la cara interna una trayectoria del pulido diferente según el sector, encontrándose mayoritariamente la siguiente disposición: vertical en la zona inferior y horizontal en la zona superior. De este modo, las líneas verticales van desde la base hasta el punto de inflexión. En el caso de las vasijas de perfil simple, las líneas verticales de pulido se presentan en la cara interna, desde la base hasta unos centímetros por debajo del borde, completándose con líneas horizontales hacia la zona superior. En la pared externa las direcciones de pulido son mayoritariamente horizontales. En las piezas decoradas el pulido se realizó en una etapa posterior a la decoración.

\section{Morfometría}

Se caracterizaron: el tipo de perfil (29\% corresponde al perfil simple y $71 \%$ al perfil compuesto), la base (el $79 \%$ son cóncavas y el $21 \%$ son planas) y el borde (en todos los casos es directo, $61 \%$ con secciones redondeadas, $34 \%$ cuadradas y $5 \%$ en bisel). Como ya se ha señalado, las medidas relevadas fueron: diámetro de la boca, diámetro de la base y altura. Los resultados obtenidos del análisis métrico indicaron que:

- El rango de variación de las medidas de la boca se extiende de $8.3 \mathrm{~cm}$ a $35.9 \mathrm{~cm}$; no obstante, 316 piezas (86\%) se encuentran entre 16 y $23.9 \mathrm{~cm}$ (Figura 9). El CV es de $18 \%$.

- El rango de variación para el diámetro de la base comprende entre $3.7 \mathrm{~cm}$ y $11.5 \mathrm{~cm}$, encontrándose 352 vasijas (96\%) entre 5 y $8.9 \mathrm{~cm}$ (Figura 10). El $\mathrm{CV}$ es de $14 \%$.
- El rango de variación para la altura es entre $4.4 \mathrm{~cm}$ y $14.5 \mathrm{~cm}$, hallándose 264 especímenes $(72 \%)$ entre 8 y $11.9 \mathrm{~cm}$ (Figura 11). El CV es de $18 \%$.

Asimismo, se establecieron relaciones entre las dimensiones de boca, altura y base (Tabla 1). Los bajos niveles observados en las medidas de dispersión (desvío estándar -DE- y coeficiente de variación) evidencian una importante uniformidad en el caso de las relaciones para las dimensiones seleccionadas.

Posteriormente se analizaron estos mismos datos seccionando la muestra por intervalos. Los mismos se determinaron a partir de la dimensión de la boca, en función del criterio establecido por Balfet y colaboradoras (1992), obteniéndose los siguientes intervalos:

1) Para el tamaño de la boca comprendido hasta 11 $\mathrm{cm}$, un $2 \%$ de la muestra.

2) Para una boca comprendida entre 11.1 y $18.9 \mathrm{~cm}$, un $30 \%$ de la muestra.

3) Para el tamaño de la boca entre 19 y $36 \mathrm{~cm}$, un $68 \%$ de la muestra.

De lo expuesto se desprende que la mayoría de los cuencos cae en la categoría "cuenco grande" y casi la totalidad en los rangos mediano a grande. El análisis separado por tamaños se realizó teniendo en cuenta que existe la posibilidad de que haya más errores en la estimación del tamaño de un objeto, que se incrementen en forma lineal con la magnitud del tamaño del producto que se intenta obtener (Roux 2003). Otra explicación puede ser que ciertos tamaños de vasijas se produzcan en menor cantidad y, por ende, los hábitos

\begin{tabular}{|l|c|c|c|}
\hline Relación & Media & Desvío estándar & Coeficiente de Variación \\
\hline Boca/Base & 3.11 & 0.52 & $16 \%$ \\
\hline Boca/Altura & 2.08 & 0.30 & $14 \%$ \\
\hline Altura/Base & 1.51 & 0.27 & $17.8 \%$ \\
\hline
\end{tabular}

Tabla 1. Relaciones entre las dimensiones de boca, altura y base. 


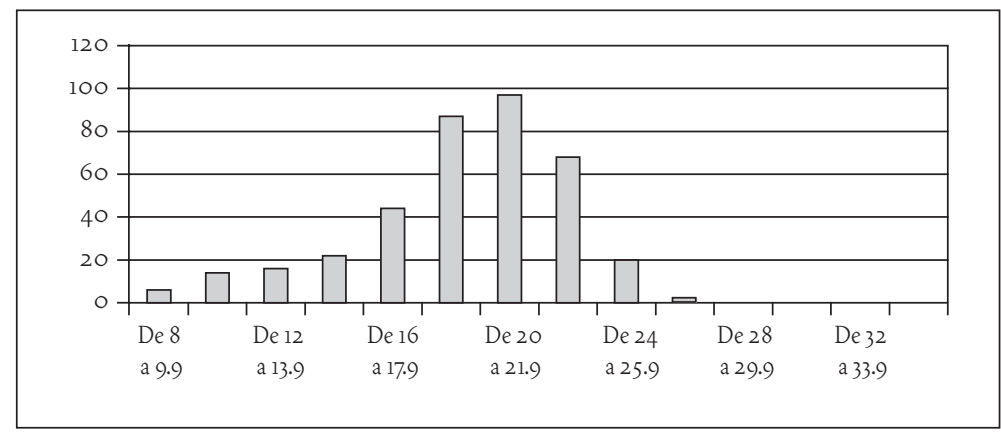

Figura 9. Gráfico que muestra el rango de variación de las medidas de la boca.

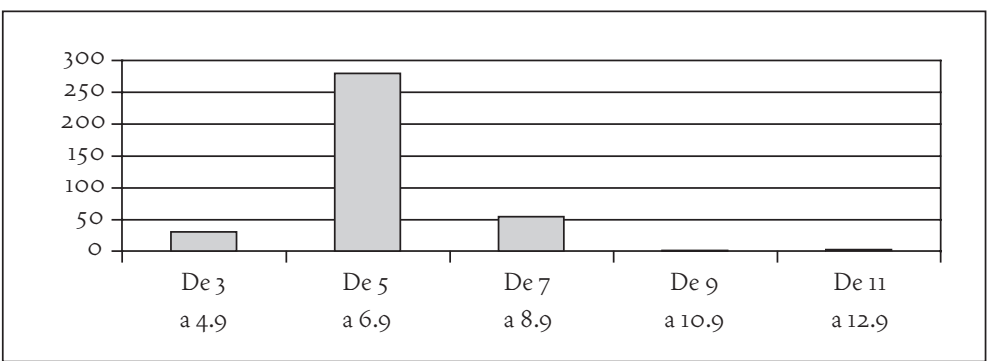

Figura 10. Gráfico que muestra el rango de variación para el diámetro de la base.

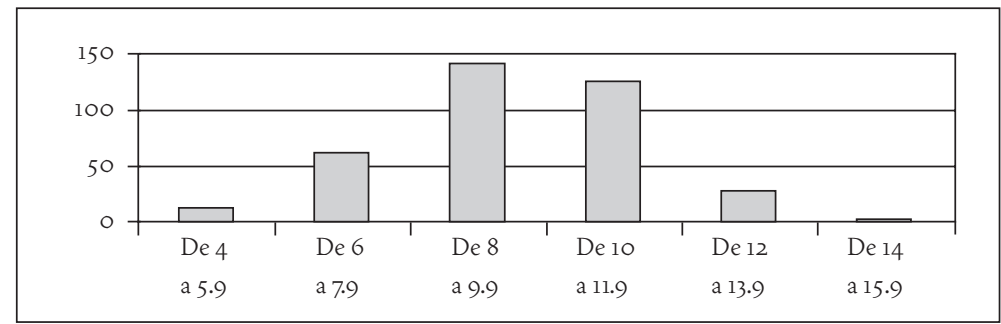

Figura 11. Gráfico que muestra el rango de variación para la altura.

motores se practican menos en dichos casos, por lo tanto, se recomienda realizar comparaciones métricas tomando en cuenta clases por tamaño. No obstante, los resultados obtenidos no reflejaron importantes diferencias en tal sentido (Tablas 2 y 3 ).

En el caso del primer grupo, según el criterio de Balfet y colaboradoras, la DE y el CV para el diámetro de la boca disminuyen debido al escaso porcentaje de piezas contenido en el grupo. Para el tercer grupo, en el diámetro de la boca también se produce una disminución, pero la misma se explica en función de que el
$66 \%$ de las vasijas de ese grupo se encuentran entre 20 y $23.9 \mathrm{~cm}$, experimentando leves diferencias de diámetro para un total de 165 piezas. Para el resto de los casos y especialmente para las relaciones entre las medidas seleccionadas, los coeficientes de variación y los desvíos estándar se mantienen dentro de los niveles registrados para el total de la muestra.

Cabe señalar que la separación se realizó siguiendo los criterios de Balfet y colaboradoras ya que no contamos con categorías émicas para efectuar otro tipo de distinción. Por otra parte, según se puede apreciar 


\begin{tabular}{|c|c|c|c|c|}
\hline \multirow{2}{*}{} & \multicolumn{3}{|c|}{ Desvío estándar } & \multirow{2}{*}{} \\
\cline { 2 - 4 } & Total & & $\mathbf{D}(\mathbf{B})$ & \\
\hline & & $1^{\mathrm{O}}$ & $2^{\mathrm{O}}$ & $3^{\mathrm{O}}$ \\
\hline $\mathrm{B}$ & 3.6 & 0.73 & 2.24 & 1.97 \\
\hline $\mathrm{b}$ & 0.97 & 0.62 & 0.86 & 0.90 \\
\hline $\mathrm{H}$ & 1.7 & 1.21 & 1.54 & 1.38 \\
\hline $\mathrm{B} / \mathrm{b}$ & 0.51 & 0.24 & 0.42 & 0.41 \\
\hline $\mathrm{B} / \mathrm{h}$ & 0.3 & 0.28 & 0.29 & 0.28 \\
\hline $\mathrm{H} / \mathrm{b}$ & 0.26 & 0.21 & 0.25 & 0.25 \\
\hline
\end{tabular}

Tabla 2. Desviación estándar para boca, base y altura y sus relaciones.

\begin{tabular}{|c|c|c|c|c|}
\hline \multirow{2}{*}{} & \multicolumn{2}{|c|}{ Coeficiente de variación } & \multirow{2}{*}{} \\
\cline { 2 - 4 } & Total & & CV $(\mathbf{B})$ & \\
\hline & & $1^{\circ}$ & $2^{\circ}$ & $3^{\circ}$ \\
\hline B & $18 \%$ & $7.4 \%$ & $14.1 \%$ & $9.1 \%$ \\
\hline b & $15 \%$ & $13.7 \%$ & $14.5 \%$ & $13 \%$ \\
\hline H & $18 \%$ & $21.3 \%$ & $18.8 \%$ & $13.5 \%$ \\
\hline B/b & $16 \%$ & $13.5 \%$ & $15 \%$ & $12.3 \%$ \\
\hline B/h & $14 \%$ & $12.7 \%$ & $14.7 \%$ & $13 \%$ \\
\hline H/b & $17 \%$ & $16.6 \%$ & $17.9 \%$ & $16 \%$ \\
\hline
\end{tabular}

Tabla 3. Coeficiente de variación para boca, base y altura y sus relaciones.

en las figuras 9 a 11, la distribución de tamaños para cada dimensión presenta curvas unimodales, lo cual indicaría que no se presentan interrupciones arbitrarias que reflejen concepciones émicas sobre categorías de tamaño.

Podemos concluir entonces, debido a la obtención de estas regularidades en las relaciones consideradas, que existe un patrón métrico preestablecido entre las distintas partes de las piezas, lo que nos permite hablar de un elevado nivel de destreza en la producción de cuencos.

A través del análisis de las relaciones entre las medidas de la boca, base y altura se detectaron constantes a partir de las cuales se verifica que el diámetro de la boca es igual a dos veces la medida de la altura y tres veces la medida de la base, y la altura representa una vez y media el diámetro de la base. La verificación de estas relaciones es independiente del tamaño de las piezas.
Lo expuesto indica que es posible establecer la existencia de un patrón métrico o canon en la manufactura de este tipo de piezas, que nos permite postular que los alfareros poseían una idea previa a la fabricación de los cuencos, que incluía tanto su morfología como proporciones fijas.

A partir de las medias halladas para cada indicador se puede establecer un cuenco promedio para La Aguada, cuyas medidas aproximadas serían: $19.5 \mathrm{~cm}$ de boca, $9.5 \mathrm{~cm}$ de altura y 6.3 de base. Un ejemplar de la muestra presenta exactamente las medidas promedio registradas (ver Figura 3).

Las evidencias que aquí se exhiben resultan coherentes con aquéllas presentadas por Laguens y Juez (2001), quienes tomaron como base la misma morfología, así como dimensiones y relaciones similares y cuyos resultados les permitieron avanzar sobre la hipótesis de la estandarización en su producción. Sin embargo, el valor del presente trabajo consiste en la importante cantidad de piezas analizadas y el conocimiento acerca de su procedencia y contextualización.

Respecto al espesor de la pared se puede observar un rango de variación entre 2.5 y $6 \mathrm{~mm}$, con una media de $3.9 \mathrm{~mm}$ y un desvío estándar de 0.17. De un total de 366 vasijas, 359 se ubican dentro de la media más los desvíos positivo y negativo, mientras que sólo siete vasijas se ubican fuera de este sector, lo cual evidencia una gran homogeneidad en el indicador analizado.

Para lograr uniformidad y delgadez en las paredes, se requieren en el ceramista condiciones de motricidad fina, que le permitan unificar el grosor a lo largo del contorno de la pieza sin que se produzcan rajaduras. Esto a su vez permite levantar una pieza simétrica y minimizar el riesgo de daño durante las etapas de secado y horneado. El registro de esta motricidad se observa en el producto final a través de la baja cantidad de piezas dañadas (estallidos, rajaduras) y/o deformadas (Figura 12). Cabe señalar que en la muestra sólo se identificaron seis cuencos con distintos grados de deformación. 


\section{Tipo de cocción}

Respecto a los cuencos grises, en efecto, los colores de las pastas en las superficies internas y externas corresponden en forma predominante a diversos matices de este color, presentando sectores más pardos y negruzcos. A pesar de registrarse en dichos casos diferencias de color dentro de una misma pieza, se puede observar una mejora técnica en el control del horneado con respecto a las vasijas funerarias de La Ciénaga (Balesta 2000; Zagorodny y Balesta 2005).

Para verificar la presencia o ausencia de núcleos de cocción se realizó un relevamiento sobre todo el universo destinado a seleccionar las piezas incompletas, en cuyos sectores fracturados resulta posible observar macroscópicamente este fenómeno. El resultado de la observación indicó que sobre 94 piezas incompletas sólo una presentaba un núcleo levemente más oscuro que el color superficial de la pasta.

Rice establece el tipo de información que se puede obtener de la observación del color de las piezas horneadas a bajas temperaturas y en condiciones en las que no se dispone de hornos. Indica que las temperaturas de cocción pueden variar en función de las localizaciones de las piezas con respecto a la fuente de calor y las corrientes de aire, y aclara que se debe ser cauto al respecto, ya que:

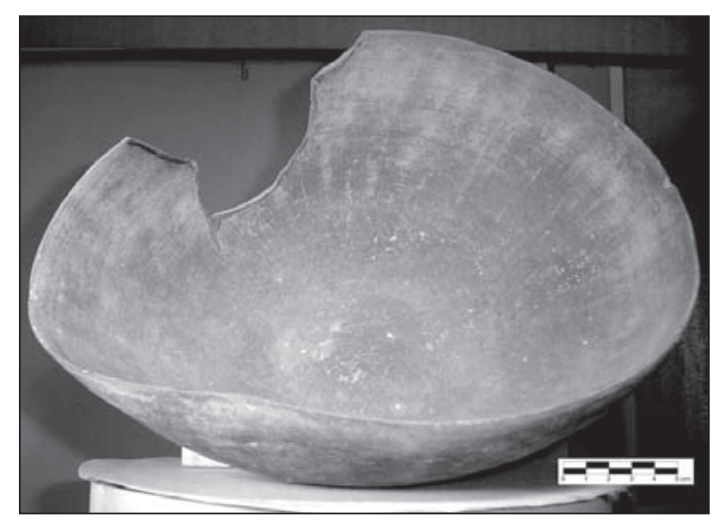

Figura 12. Pieza deformada por defectos de manufactura.
"[...] it could be argued that standardized measurement of color of non-kiln-fired sherds represents false precision, because the original conditions through which the colors were developed were uncontrolled and highly variable" (1987:345).

Sin embargo, teniendo en cuenta el color de la superficie y del núcleo en función de las relaciones que establece la autora entre el color observable y las condiciones originales de cocción se pueden realizar algunas inferencias. En nuestro caso, considerando que los colores de superficie son generalmente tonalidades que abarcan grises más claros o más oscuros y núcleos mayoritariamente del mismo color de la pasta de superficie o relativamente más oscuros, podemos inferir que las condiciones de horneado fueron oxidantes o reductoras incompletas.

La cantidad de cuencos pintados es considerablemente menor que la de aquéllos con decoración incisa, tanto en el universo como en la muestra. En nuestro caso sólo 20 ejemplares son pintados, de los cuales muy pocos presentan fracturas que permitan analizar los núcleos de cocción. Sin embargo, no se han observado núcleos de cocción y los colores son homogéneos en toda la superficie yendo del ante y el amarillento al rojizo, por lo cual se podría inferir una cocción con atmósfera oxidante.

Cabe destacar que dentro del conjunto de piezas pintadas existe una porción que presenta su interior de un color negro bruñido. Sempé y Albeck (1981) ya se han referido a este tipo de piezas, señalando que el negro bruñido implicaría, ya sea una técnica de cocción particular o la aplicación de la técnica del "grafitado" (De la Fuente et al.2005), si bien no existen estudios concluyentes al respecto.

Respecto a las técnicas de cocción, González (1998) señala que los tipos alfareros de La Aguada son de mejor calidad en relación con los que los precedieron, ya que tienen pastas más firmes y de mejor sonoridad: "Quizás mejoró la pirotecnia cerámica, aunque ésta ya estaba bien desarrollada en Condorhuasi-Alamito, que les permitía fundir la aleación de bronce. Esta técnica pudo aplicarse luego a la cerámica" (1998: 75-76). 


\section{Técnica decorativa}

Se registró el tipo de decoración (incisa o pintada) y el modo de realización. La técnica más utilizada fue la incisión ( $72 \%$ del total de vasijas), y en mucho menor cantidad ( $6 \%$ del total), la pintura.

Cuencos con decoración incisa. La incisión es definida según la Primera Convención Nacional de Antropología (1966:65) como una "técnica decorativa que consiste en trazar diseños [...] con un instrumento sobre la pasta aún blanda ya sea plástica o con la consistencia de cuero". Sobre las piezas decoradas con incisión se registraron diversos aspectos como grosor de la incisión, herramientas utilizadas, sección de la misma, relieve y residuo. Se distinguieron incisiones con un grosor de 1 a $2 \mathrm{~mm}$ y otras con un grosor menor a $1 \mathrm{~mm}$. Las primeras delimitan motivos, mientras que las segundas rellenan el diseño. Las incisiones fueron realizadas mediante herramientas punzantes de punta simple o múltiple (de tres a seis puntas) en forma de peine. El mismo fue utilizado principalmente para rellenar figuras y en algunas piezas para realizar la totalidad del diseño. El peine fue utilizado por arrastre, dejando incisiones paralelas o por presión, imprimiendo puntos alineados. Se observaron variaciones tanto en el espacio entre las incisiones como en el número de líneas dejadas por el peine. Esto nos permite suponer que se utilizó un peine al cual se sujetaron puntas flexibles, o que se usaron puntas sueltas sujetas con la mano. A su vez, con el peine fijo pueden existir variaciones menores en el ángulo de arrastre.

La sección de la incisión puede ser de dos tipos, redondeada (21\%) o triangular (79\%) dependiendo del tipo de punta utilizada o del ángulo en que se realiza la incisión. La sección de la incisión se relaciona en forma directa con el tipo de punta utilizada y con el ángulo en que se aplica la herramienta con respecto a la superficie, aunque se ha observado que si el ángulo es menor se provocará una sección redondeada, independientemente de la forma de la punta que se use. En este último caso, cuando la pasta contiene material antiplástico, el procedimiento mencionado no lo arranca, sino que lo va acomodando, dejando un surco redondeado y liso cuyos bordes presentan una mínima rebarba.

El relieve de la incisión depende del estado de humedad de la pasta en el momento en que se realiza, presentando rebarba cuando se produce sobre la pasta en estado húmedo a "cuero", o bordes netos cuando es sobre pasta firme a seca. Los bordes netos también pueden ser logrados por la eliminación posterior de la rebarba, pudiendo o no, dejar huella. La evidencia depende de varios factores: el estado de humedad, el grosor de la rebarba y la forma de eliminación. Si la rebarba se elimina en estado "cuero" por pulido de la superficie incisa, se puede producir una deformación de la línea de incisión y a su vez el material residual puede tapar el surco. En estado seco, la eliminación de la rebarba depende de su grosor. Si es delgada se desprende fácilmente frotando la superficie; si es gruesa raspando la misma con una herramienta. Esta última acción deja como rastro una diferencia de color en la zona de eliminación, respecto del resto de la superficie. El residuo del arrastre provocado al incidir, queda al costado o al final de la incisión. Su presencia o no en la pieza cerámica es una decisión del alfarero.

Cuencos con decoración pintada. Se observó un alto grado de homogeneidad en la ejecución de los diseños y en la utilización de los colores. Los trazos se ejecutaron con precisión y su grosor es uniforme (ver Figura 6). Respecto a los pigmentos utilizados existen diversos criterios y técnicas para identificar su composición. Pueden ser de tipo visual directo o a través de la aplicación de técnicas físicas y/o químicas (Hawley 1929; Shepard 1939, 1980 [1956]; Stewart y Adams 1999).

Utilizamos el criterio visual para evaluar las piezas, ya que por tratarse de piezas de colección no se pueden utilizar técnicas destructivas. Stewart y Adams (1999) establecen un conjunto de indicadores visuales para determinar el tipo de pintura utilizada en piezas arqueológicas del suroeste de Estados Unidos, los cuales incluyen: color, nitidez, grosor, ancho de las pinceladas, sumersión o suspensión de las mismas con respecto a la superficie y conservación de la pintura. 
De acuerdo a estos indicadores se determinaron las siguientes constantes:

- Los colores utilizados son el negro -en forma mayoritaria-y el rojo.

- Los diseños muestran trazos de bordes netos.

- La pintura aparece gruesa.

- La pintura se sitúa sobre la superficie.

- No hay señales de escamado de la pintura.

Por otra parte, desde el punto de vista técnico se observaron pinceladas que dan forma a los contornos del dibujo, que luego fueron rellenados. Por lo tanto, los bordes del diseño presentan mayor densidad de la pintura con respecto al interior. El pulido está por encima de la pintura, dando el mismo efecto de brillo en toda la superficie de la vasija. En los casos en que la pintura negra exhibe efectos de fotoenvejecimiento la misma va virando hacia tonalidades amarronadas, siendo siempre más densos los bordes que los interiores de los diseños, en los que se puede ver, por transparencia, el color ante de la base. Cuando la pieza es policroma - roja y negra sobre ante- las líneas pintadas en ambos colores se alternan o el rojo puede rellenar un diseño contorneado en negro. Los trazos fueron ejecutados con el mismo pincel. Si el diseño es más grueso, se trabajó cubriendo la superficie por yuxtaposición de pinceladas.

A través de las características registradas, y siguiendo los criterios establecidos por Stewart y Adams (1995), se infiere que se utilizaron pinturas minerales para la decoración de las vasijas, lo cual se refuerza por otras evidencias de los contextos funerarios del cementerio La Aguada Orilla Norte (Zagorodny et al.2002), como los panes de pigmentos hallados en algunas unidades de entierro. Los mismos fueron analizados a través de estudios mineralógicos por difracción de rayos $\mathrm{X}$ y de microscopía electrónica de barrido, indicando básicamente la presencia de óxidos de hierro en su composición.

Por otra parte, estudios sobre pigmentos realizados sobre piezas Aguada Portezuelo para sitios del valle de Catamarca (De la Fuente et al. 2005) y Choya 68
(Cremonte et al. 2003) han dado como resultado la utilización de pigmentos minerales con altos contenidos en fierro y manganeso.

\section{$\diamond$ Discusión}

La estandarización habitualmente se considera como una reducción en la variedad de la conducta de los artesanos y/o de los productos. La existencia de homogeneidad en la utilización de materias primas, en los métodos de manufactura y en el tamaño, la apariencia y la decoración dentro de un conjunto de piezas constituye un índice adecuado para estimar la estandarización en la producción cerámica. Teniendo en cuenta que para los estudios de estandarización es necesario establecer niveles de análisis que consideren que pueden manifestarse rangos de diversidad atribuibles a diferentes contextos y en diferentes períodos, nuestro estudio resulta pertinente, al estar considerando sólo cerámica funeraria adscrita al período de desarrollo de la entidad cultural Aguada y una sola morfología representada por los cuencos. La muestra seleccionada es apta para este estudio ya que comprende vasijas adscritas a un período que si bien duró varios siglos mantuvo un grado importante de homogeneidad estilística, que permite adscribir las piezas con facilidad. Por otra parte, se seleccionaron aspectos de la variabilidad que reflejan patrones inconscientes, destrezas motoras y leves diferencias tecnológicas; además de las variables métricas, que se consideran apropiadas en esta clase de análisis.

Si bien admitimos que los estudios composicionales son importantes en la determinación de la estandarización, en nuestro caso no fueron posibles porque tratamos piezas de colección, por lo cual se recurrió a otros aspectos tecnológicos así como a los morfométricos, a fin de producir resultados complementarios. De todos modos, el universo considerado presenta varias ventajas, como proporcionar un número muy elevado de piezas completas o casi completas, a lo que se suma la existencia de un soporte documental que posibilita su contextualización y el registro de sus condiciones de hallazgo. 
Los estudios etnográficos y etnoarqueológicos (Blackman et al. 1993; Longacre 1999; Roux 2003) referidos a estandarización indican que sobre la variabilidad influyen tanto la tasa de producción como las concepciones émicas de estandarización. Los resultados obtenidos en dichos estudios indican que cuando el CV en las medidas de las vasijas varía entre 6\% y $9 \%$ las mismas pueden pertenecer a una escala de producción pequeña. Cabe señalar que los conjuntos allí analizados se hicieron en menos de 10 eventos de producción, correspondiendo un evento a un ceramista. Sin embargo, cuanto más valores de ceramistas se promedien, mayor será el efecto acumulativo del CV. Cuando se miden los coeficientes de variación sobre piezas arqueológicas habitualmente se toma en cuenta la profundidad temporal de la muestra (Costin y Hagstrum 1995) y se considera que el CV debe ampliarse si los conjuntos pertenecen a eventos de producción alcanzados a través de varios siglos.

Blackman y colaboradores (1993) realizaron estudios métricos sobre cuencos arqueológicos en Mesopotamia que arrojaron valores de CV de $18 \%$. Si bien dichos valores parecen demasiado elevados, de todos modos se los consideró como una producción estandarizada y su magnitud se imputó al efecto acumulativo de 200 años de producción, atribuyendo el grado de variabilidad a una producción no centralizada. Dichos valores resultan consistentes con los hallados por nosotras para dos de las medidas (diámetro máximo y altura) y menores en una de ellas (diámetro de la base). La magnitud en nuestro caso se podría deber a los efectos de promediar la producción en un lapso aproximado de 400 años y, de acuerdo a los datos disponibles para nuestro período, a una producción no centralizada.

Por otra parte, la estandarización se ha relacionado con el ciclo de vida de cada tipo de artefacto y se considera que, entre otros factores, puede reflejar destreza de los productores, conductas de aprendizaje y replicación, número de productores y preferencias de los consumidores (Rottlander 1966; Longacre et al. 1988; Arnold 1991; Rice 1991; Blackman et al. 1993; Costin y Hagstrum 1995; Longacre 1999, entre otros).
Para evaluar la destreza relativa de los artesanos se suelen tomar dos aspectos técnicos de la manufactura: grosor de las paredes y núcleos de cocción (Costin y Hagstrum 1995). El grosor de las paredes puede proporcionar una idea de la destreza en el modelado de la pieza y subsecuentes modificaciones en la superficie. La presencia o ausencia de núcleo de cocción se considera un indicador del nivel de control y consistencia en el horneado. Se suele asumir que una relativa homogeneidad en las características de horneado refleja el número de unidades de trabajo, ya que cada grupo tendrá su propia técnica de horneado, que incluirá los preparativos previos, combustibles usados y claves para determinar el principio y fin del proceso. Los resultados de nuestro análisis indican que, en general, no se observan núcleos de cocción y que cuando ello ocurre los mismos son apenas más oscuros que las pastas de las vasijas grises; en el caso de las vasijas sometidas a cocción oxidante no se registraron núcleos de cocción, lo cual indicaría un control del proceso de cocción y una mejora respecto a períodos anteriores (Zagorodny y Balesta 2005).

En estrecha relación con la destreza se encuentra la transmisión del conocimiento sobre la producción alfarera. En tal sentido se puede postular que en este caso la tradición se ha transmitido, lo cual se verifica a partir de la continuidad de la fabricación del mismo tipo de piezas durante varios cientos de años y en la existencia de vasijas que muestran la práctica de manos aún inexpertas en la fabricación, a través de defectos en la morfología y la decoración; tal es el caso de la vasija de la Figura 13 en la cual se evidencian imprecisiones en la decoración y de la Figura 8 en la cual se observan defectos tanto en la decoración como en la manufactura de la pieza.

Aún sin necesidad de que el número de productores de cerámica sea lo suficientemente reducido como para pensar en una producción especializada, la manufactura de las piezas puede ser estandarizada (Roux 2003). Esto se puede deber a razones diversas, ya sea porque resulta más eficiente producir de este modo, por ejemplo, requiriendo de una menor cantidad de toma de decisiones conscientes con respecto al diseño 


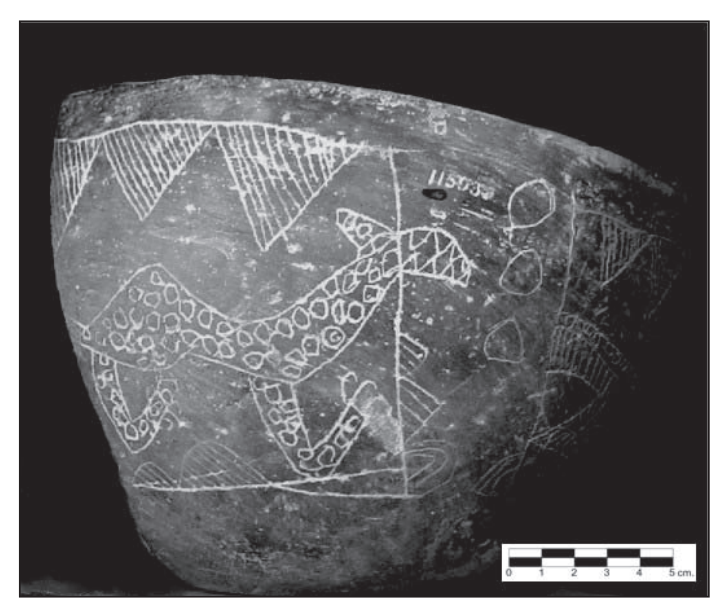

Figura 13. Puco con imprecisiones en la decoración.

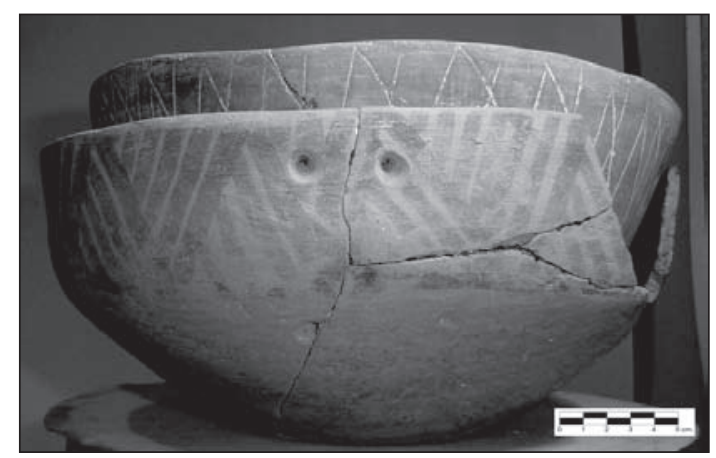

Figura 14. Ejemplo de pucos hallados apilados dentro de una tumba.

subyacente, o por demanda de los consumidores, como se verifica en situaciones en las que el estilo comunica importante información acerca de estatus social, afiliación grupal, etc. En dichas situaciones la estandarización es un mandato social y no económico (Costin 1991). En nuestro caso, es en el ámbito funerario donde la transmisión de cierto tipo de información podría resultar de crucial importancia en la consideración de la manufactura de las piezas y se puede interpretar su homogeneidad como producto de un mandato social.

Además de buscarse la eficiencia en el proceso de producción, de la manufactura de productos estandarizados pueden obtenerse otros beneficios, como por ejemplo, el hecho de que los objetos son más fáciles de almacenar, embalar y transportar. Si se considera que la morfología de los cuencos en sí misma resulta una condición ampliamente favorable para el apilamiento, a esto se suma el hecho de que el apilamiento de las vasijas de La Aguada Orilla Norte haría más fácil el transporte al lugar de la inhumación. Por otra parte, se ha constatado que dentro de las tumbas, muchos ejemplares se encontraron dispuestos unos dentro de otros (Figuras 2 y 14 ).

Los estudios sobre datos indirectos raramente indican información acerca de la organización específica de la producción, pero nos pueden informar sobre el grado relativo de especialización de un producto específico y de este producto en la economía en general (Costin 1991). La variación regional nos provee de una medida del grado de especialización a gran escala, porque podemos asumir que las diferentes variantes serán los productos de diferentes grupos de producción; durante períodos con escasas variantes regionales se puede inferir un alto grado de especialización, con pocos grupos de producción. Los períodos caracterizados por muchas variantes regionales reflejan un bajo grado de especialización porque hay muchos grupos produciendo para la misma región. En este trabajo se trata un período de aproximadamente 400 años, con la expresión de diversas localidades que usaron un lugar de entierro común. Por ello se puede suponer que la escasa variación regional implicaría un número reducido de productores especializados en la manufactura de un producto funerario.

Se ha postulado que cuando una región amplia consume un producto homogéneo existen mayores probabilidades de que la fabricación esté más concentrada (Costin 1991). El cementerio La Aguada Orilla Norte estaría representando el lugar de entierro de varias localidades del valle de Hualfín, exhibiendo una homogeneidad considerable que podría provenir de la manufactura de un número restringido de unidades de producción. De todos modos, para asumir la conexión entre la estandarización identificada y la especialización en la organización productiva se necesitaría mayor evidencia, que también involucre aspectos referentes a su escala e intensidad. 
En el mismo período que nos ocupa, Laguens y Bonnin (2005) establecen que la producción cerámica debió haber sido especializada en el valle de Ambato y la relacionan con otros indicadores de desigualdad social. Identifican la presencia de tres grupos cerámicos en distintas clases de sitios de dicho valle, observando que en la producción alfarera:

“[... existió una concentración de esfuerzos hacia la producción de ciertas piezas de alto valory dedicación artesanal, junto con cánones estandarizados de forma y tamaño en piezas de uso generalizado en todo el valle. Creemos que el mantenimiento de una producción tal respondió a prácticas estandarizadas que, dada su dedicación de tiempo, especialización y grado de maestría, puede estar señalando diferencias permanentes entre las personas en cuanto a su dedicación laboral, muy probablemente concentrada sólo en ciertos sectores de la sociedad" (2005:28).

En el cementerio La Aguada Orilla Norte la gran cantidad de cuencos registrada nos permite establecer la perdurabilidad de esta morfología, con su correspondiente decoración, a lo largo del tiempo. Las regularidades detectadas en la morfometría, en la decoración y en el control de cocción implicaron una reducción en el rango de variabilidad de los cuencos, lo cual hace suponer que la técnica de manufactura fue transmitida casi sin variantes de generación en generación. Sumado a esto, el período de utilización del cementerio de donde proceden las vasijas analizadas implica que este importante grado de estandarización se puede asignar a varios eventos de producción dentro de dicho período y al efecto de la demanda de un tipo particular de producto destinado a la esfera funeraria.

Como se ha reseñado, diversos autores han postulado a la estandarización como un posible indicador de especialización en la producción cerámica y que, a su vez, la especialización se halla en estrecha relación con la complejidad social. En tal sentido, Laguens (2007) ha establecido que la producción alfarera de Aguada:

"[...] se basaba en pautas muy acotadas de manufactura y decoración, que no sólo imponían diseños y contenidos, sino también limitaciones o normas en la fabricación con respecto a formas y tamaños, las que requirieron de una dedicación significativa de tiempo y una serie de conocimientos específicos, que sólo pudieron haber sido hechos por alfareros especializados" (2007: 28).

Esperamos que este trabajo aporte a la caracterización de la entidad sociocultural Aguada, profundizando en la comprensión de la complejidad de estos grupos sobre la base de su organización en la producción cerámica.

Agradecimientos A la Srta. María José Gómez Ferreiro por sus aportes en la experimentación sobre manufactura y decoración cerámica.

\section{Referencias citadas}

Allen, K., 1992. Iroquois ceramic production: A case study of household-level organization. En Ceramic production and distribution: An integrated approach, G. J. Bey III y C. A. Pool (Eds.), pp. 133-154. Westview Press, Boulder.

ARNOLD, P., 1991. Dimensional standardization and production scale in Mesoamerican ceramics. Latin American Antiquity $2(4): 363-370$.

Arnold, D. y A. L. Nieves, 1992. Factors affecting ceramic standardization. En Ceramic production and distribution: An integrated approach, G. J. Bey III y C. A. Pool (Eds.), pp. 113-214. Westview Press, Boulder.
Balesta, B., 2000. La significación en la funebria de La Ciénaga. Tesis Doctoral. Facultad de Ciencias Naturales y Museo, Universidad Nacional de La Plata, La Plata.

Balfet, H., M. Fauvet-Berthelot y S. Monzon, 1992. Normas para la descripción de vasijas cerámicas. Centre D’Etudes Mexicaines et Centraméricaines, México D. F.

Benco, N., 1988. Morphological standardization: An approach to the study of craft specialization. En $A$ pot for all reasons, ceramic ecology revisited, C. Kolb y L. Lackey (Eds.), pp. 57-72. Temple University, Pennsylvania. 
Blackman, M. J., G. J. Stein y P. B. Vandiver, 1993. The standardization hypothesis and ceramic mass production: Technological, compositional and metric indexes of craft specialization at Tell Leilan, Syria. American Antiquity 58 (1): $60-80$.

Callegari, A., 2006. La complejidad social, el paisaje construido y los ritos de convalidación del poder en La Cuestecilla. La Rioja (depto. de Famatina). Actas de la IV Mesa Redonda "La Cultura de La Aguada y su dispersión", pp. 137-150. Instituto de Investigaciones Arqueológicas y Museo, Universidad Católica del Norte, San Pedro de Atacama.

CARO, M., 2006. Arquitectura del sitio Piedras Blancas: ¿Tradición o innovación? Actas de la IV Mesa Redonda "La Cultura de La Aguada y su dispersión", pp. 29-41. Instituto de Investigaciones Arqueológicas y Museo, Universidad Católica del Norte, San Pedro de Atacama.

Costin, C. L., 1991. Craft specialization: Issues in defining, documenting and explaining the organization of production. EnAdvances of archaeological method and theory, vol.3. M. Schiffer (Ed.), pp. 1-56. University of Arizona Press, Tucson.

Costin, C. L. y M. Hagstrum, 1995. Standardization, labor investment, skill and the organization of ceramic production in Late Prehispanic Highland Peru. American Antiquity $60(4): 619-639$

Cremonte, M. B., M. Baldini y L. Botto, 2003. Pastas y colores, un camino al conocimiento del estilo Portezuelo de Aguada. Intersecciones en Antropología 4: 3.16.

De La Fuente, G., N. Kristcautzky, G. Toselli y A. Riveros, 2005. Petrología cerámica comparativa y análisis composicional de las pinturas por MEB-EDS de estilo Aguada Portezuelo (ca. 600-900 DC) en el valle de Catamarca (Noroeste Argentino). Estudios Atacameños 30: 61-78.

Eerkens, J. y R. Bettinger, 2001. Techniques for assessing standardization in artifact assemblages: Can we scale material variability? American Antiquity 60 (3): 493-504.

GonzÁlez, A. R., 1972. The felinic complex in Northwest Argentina. En The cult of the feline, E. Benson (Ed.), pp. 117138. Dumbarton Oaks, Washington D. C.

1977. Arte precolombino en la Argentina. Filmediciones Valero, Buenos Aires.

1961-64. La cultura de La Aguada del Noroeste Argentino. Revista del Instituto de Antropología 2-3: 283-297.

1998. Cultura La Aguada. Arqueología y diseños. Filmediciones Valero, Buenos Aires.
GonzÁlez, A. R. y G. Cowgill, 1975. Cronología del valle de Hualfín, provincia de Catamarca, obtenida mediante el uso de computadoras. Actas del Primer Congreso Nacional de Arqueología Argentina (1970), pp. 383-404. Rosario.

Gordillo, I., 1994. Arquitectura y religión en Ambato: Organización socioespacial del ceremonialismo. Arqueología 47: 55-110.

2006. Espacio y rito. Aproximaciones a la construcción del paisaje La Aguada. Actas de la IV Mesa Redonda "La Cultura de La Aguada y su dispersión", pp. 67-83. Instituto de Investigaciones Arqueológicas y Museo, Universidad Católica del Norte, San Pedro de Atacama.

Kvamme, K, M. Stark y W. Longacre, 1996. Alternative procedures for assessing standardization in ceramic assemblages. American Antiquity 61 (1): 116-126.

Hawley, F., 1929. Prehistoric pottery pigments. American Anthropologist 31: 731-754.

Lafone Quevedo, S., 1892. Catálogo descriptivo e ilustrado de las Huacas de Chañar-Yaco. Revista del Museo de La Plata $3: 33-63$.

1908. Tipos de alfarería de la región diaguita-calchaquí. Revista del Museo de La Plata 15 ( ${ }^{\text {a }}$ Serie, 2): 295-395.

Laguens, A., 2007. Contextos materiales de desigualdad social en el valle de Ambato, Catamarca, Argentina, entre los siglos VII y X DC. Revista Española de Antropología Americana 37 (1): 27-49.

Laguens, A. y M. Bonnin, 2005. Recursos materiales y desigualdad social en la arqueología de Ambato-Catamarca. En La cultura de La Aguada y sus expresiones regionales, S. Martín, M. E. Gonaldi, S. Ferraris y A. Giordano (Eds.), pp. 23-33. Eudelar, La Rioja.

Laguens, A. y S. Juez, 2001. Especialización en la manufactura cerámica de pucos Aguada. Actas del XIII Congreso Nacional de Arqueología Argentina, vol. 1, pp. 489-504. Córdoba.

LONGACRE, W., 1999. Standardization and specialization: What's the link? En Pottery and people, J. Skibo y G. Feinman (Eds.), pp. 44-53. University of Utah Press, Salt Lake City.

Longacre, W., K. L. Kvamme y M. Kobayashi, 1988. Southwestern pottery standardization: An ethnoarchaeological view from the Philippines. Kiva 53:101-112.

NúÑez, L.y T. DillehaY, 1995 [1979]. Movilidad giratoria, armonía social y desarrollo en los Andes meridionales: Patrones de tráfico 
e interacción económica. Universidad Católica del Norte, Antofagasta.

Pérez Gollán, J., 2000. El jaguar en llamas. La religión en el antiguo Noroeste Argentino. En Nueva historia argentina, vol. 1. M. Tarragó (Ed.), pp. 229-256. Editorial Sudamericana, Buenos Aires.

Primera ConVEnCión NACIONAL de Antropología, 1966. Facultad de Filosofía y Humanidades, Córdoba.

RicE, P., 1981. Evolution of specialized pottery production: A trial model. Current Anthropology 22 (3): 219-240.

1987. Pottery analysis. A sourcebook. University of Chicago Press, Chicago.

- 1991. Specialization, standardization and diversity: A retrospective. En The ceramic legacy of Anna Shepard, R. Bishop y F. Lange (Eds.), pp. 257-279. University Press of Colorado, Boulder.

RotTLANDER, R. C., 1966. Is Provincial-Roman pottery standardized? Archaeometry 9: 76-91.

Roux, V., 2003. Ceramic standardization and intensity of production: Quantifying degrees of specialization. American Antiquity 68 (4): 768-782.

Sempé, C. y M. E. Albeck, 1981. La cerámica de interior negro bruñido en el Noroeste Argentino. Su ubicación espaciotemporal y cultural. Revista Española de Antropología Americana 11: 161-181.

SHEPARD, A., 1939. Technology of La Plata pottery. En Archaeological studies in the La Plata District Southwestern Colorado and
Northwestern New Mexico, E. Morris (Ed.), pp. 249-287. Carnegie Institution, Washington D. C.

1980 [1956]. Ceramics for the archaeologist. Publication 609, Carnegie Institution of Washington, Washington D. C.

Sinopoli, C., 1999. Levels of complexity: Ceramic variability at Vijayanagara. En Pottery and people, J. Skibo y G. Feinman (Eds.), pp. 115-136. University of Utah Press, Salt Lake City.

Stark, B., 1995. Problems in analysis of standardization and specialization in pottery. En Ceramic production in the American Southwest, B. Mills y P. Crown (Eds.), pp. 231-267. University of Arizona Press, Tucson.

SteWArt, J. y K. AdAms, 1999. Evaluating visual criteria for identifying carbon and iron-based pottery paints from the Four Corners Region using SEM-EDS. American Antiquity 64 (4): 675-696.

Wolters, F., 1928-29 Ms. Correspondencia y libretas de campo expediciones al Noroeste Argentino. Departamento Científico Arqueología, Museo de La Plata, La Plata.

Zagorodny, N. y B. Balesta, 2005. Estudio multidimensional de la alfarería de La Ciénaga. En Azampay. Presente y pasado de un pueblito catamarqueño, C. Sempé, S. Salceda y M. Maffia (Eds.), pp. 267-288. Ediciones Al Margen, La Plata.

Zagorodny, N., B. Balesta, P. Zalba y M. Morosi, 2002. La confección de pigmentos en la producción de cerámica arqueológica (La Aguada, Catamarca, Argentina). Relaciones de la Sociedad Argentina de Antropología XXVII: 177-193. 